Rev. Interd. em Cult. e Soc. (RICS), São Luís, v. 7, n. 2, p. 214- 223, jul./dez. 2021 ISSN eletrônico: $2447-6498$

\title{
Motivação e experiência educacionais dos alunos e professores no contexto de ferramentas digitais no período de pandemia ${ }^{1}$
}

\section{Motivation and educational experience of students and teachers in the context of digital tools in the pandemic period.}

\author{
LUIZ MANOEL LOPES \\ Doutor em Filosofia pela Universidade Federal de São Carlos (UFSCar) \\ manoel.lopes@ufca.edu.br
}

JOSEDETE GONÇALVES XAVIER

Mestranda do PPGB -Programa de Pós-graduação em Biblioteconomia da Universidade Federal do Cariri (UFCA) - Juazeiro do Norte josedete.xavier@ufca.edu.br

AUDIVANIA RODRIGUES DA SILVA Mestranda do PPGB - Programa de Pós-graduação em Biblioteconomia da Universidade Federal do Cariri (UFCA) - Juazeiro do Norte audivania@gmail.com

\begin{abstract}
RESUMO
O presente artigo aborda a experiência educacional em tempos de pandemia, na relação bilateral aluno e professor, frente às novas ferramentas digitais. O objetivo é apresentar o ambiente familiar como motivação para o aluno, buscando lançar um novo olhar para a prática pedagógica, voltada para ferramentas educacionais e tecnologias digitais. Nesse novo cenário, percebemos também novos hábitos do aprendizado. A metodologia do presente estudo, de caráter descritivo e exploratório, aborda estudo bibliográfico e documental em que se discutem as contribuições das tecnologias digitais para a motivação dos alunos diante do processo de aprendizagem no momento em que se enfrenta a pandemia do novo Coronavírus. $\mathrm{O}$ artigo traz como contribuição uma breve análise do processo de aprendizagem da relação bilateral e do conhecimento prático através das ferramentas tecnológicas, novas habilidades pedagógicas, e no desenvolvimento educacional tecnológico.
\end{abstract}

Palavras-chaves: Ambiente motivador. Ferramentas tecnológicas. Habilidades tecnológicas. COVID-19.

\begin{abstract}
This article discusses the educational experience in times of pandemic, in the bilateral relationship between student and teacher, in the face of new digital tools. The objective is to present the family environment as motivation for the student, seeking to launch a new look at pedagogical practice, focused on educational tools and digital technologies. In this new scenario,
\end{abstract}

\footnotetext{
${ }^{1}$ Artigo submetido para avaliação em 25 de agosto de 2021 e aprovado em 12 de novembro em 2021.
} 
Rev. Interd. em Cult. e Soc. (RICS), São Luís, v. 7, n. 2, p. 214- 223, jul./dez. 2021 ISSN eletrônico: $2447-6498$

we also noticed new learning habits. The methodology of this study, of descriptive and exploratory character, addresses bibliographic and documentary study in which the contributions of digital technologies to the motivation of students in the learning process are discussed at the moment when the pandemic of the new Coronavirus is faced. A brief analysis of the learning process of the bilateral relationship and practical knowledge through technological tools, new pedagogical skills, and technological educational development.

Keywords: Motivating environment. Technological tools. technological skills.

\section{INTRODUÇÃO}

Com o início da pandemia do COVID-19, em todo o país, ocorreu um processo de suspensão das aulas para conter a proliferação da transmissão do vírus. Diante deste novo cenário, portador de novos desafios, dá-se a grande questão: como continuar com as aulas $e$ garantir o direito ao aprendizado dos discentes em situação de pandemia, visto o enfrentamento de muitas adversidades? Em março de 2020, a Organização Mundial de Saúde (OMS) declarou que o mundo estava vivendo uma pandemia e medidas precisavam ser pensadas para impedir que houvesse uma rápida disseminação do novo Coronavírus (COVID-19) pelo mundo.

A partir do relatório da Organização para a Cooperação e Desenvolvimento Econômico (OCDE), foi proposto aos líderes dos sistemas e organizações educacionais que desenvolvessem planos e programações para a continuidade dos estudos por meio de novas formas de aprendizado, enquanto durar o período de isolamento social, haja vista a necessidade de manter a educação das crianças, jovens e adultos.

No Brasil, a propagação do vírus foi acelerada. Os governos estadual e municipal têm imposto à população cearense decretos com medidas importantes para combater a disseminação do Coronavírus, submetendo todo o Estado ao isolamento social. No primeiro momento, a educação foi redesenhada através de meios eletrônicos, como: celular, computador, televisão, meios tecnológicos para o ensino-aprendizagem dos discentes. Através das ferramentas digitais citadas, as famílias tiveram que se adaptar e criar um novo ambiente com motivações para a aprendizagem dos filhos em tempo de pandemia. Este cenário colocou como um dos desafios que pais, professores e alunos estão enfrentando ao longo desse período, como a falta de suporte ou orientações, ocasionando conhecimentos teóricos e práticos precários destas ferramentas digitais.

Todavia, a educação passou por mudanças relevantes, consequentemente, as vidas e os hábitos dos discentes tiveram que ser adaptados à nova realidade sem aula presencial, sem o 
Rev. Interd. em Cult. e Soc. (RICS), São Luís, v. 7, n. 2, p. 214- 223, jul./dez. 2021 ISSN eletrônico: 2447-6498

docente e sem ferramentas necessárias para as aulas de qualidades, porque muitos dos professores também não são possuidores do conhecimento dessas ferramentas digitais. O ensino remoto emergencial aconteceu sem nenhum planejamento prévio tanto pelos docentes como pelos discentes e familiares. Neste sentido, o uso da tecnologia da informação como meio educativo foi negligenciada para os distintos públicos que agregam a cadeia no processo educacional, segundo (CORDEIRO, 2020, p. 02).

Neste sentido, e com o intuito de manter as atividades educacionais durante o período de isolamento social, muitas instituições adotaram o ensino remoto, no qual os educadores tiveram que adaptar seus conteúdos para o formato online. Essas atividades online direcionadas aos alunos, apesar de todos os seus desafios e entraves, são cruciais para minimizar os prejuízos do período na ausência das aulas presenciais.

A interrupção das aulas e o fechamento das escolas foi feita com a preocupação de proteger os estudantes da transmissão do vírus e possivelmente deles serem vetores para suas famílias e comunidade, inclusive para as pessoas mais vulneráveis a comedidas. Numa tentativa de solucionar a problemática da educação com o fechamento das escolas, diminuindo os impactos no ensino e aprendizagem dos alunos, as secretarias de educação do estado e municípios criaram plataformas, com a parceria de professores para elaboração que ajudasse na preparação de conteúdo, oferecendo aulas online.

"O interessante é que muitas famílias estão acompanhando os filhos, neste momento de pandemia, tem nas mãos a possibilidade de compreender a importância do seu papel na educação destes, e ainda de valorizar o professor" (CORDEIRO, 2020, p. 03). Como percebemos, a educação a distância (EAD), em tempo de pandemia, tem sido a prioridade dos nossos governantes para atender os contingentes populacionais em idade escolar. Defendendo essas estratégias, os municípios e estados buscam juntos aos genitores a promoção do ensino online, que exige dos pais maior responsabilidade no acompanhamento de suas atividades escolares.

Nesta perspectiva, como lidar com a transição entre ensino presencial para o novo método de ensino online, o qual requer ferramentas de informação e planejamentos inovadores, bem como investimentos, os quais não será possível em curtíssimo prazo? No entanto, nessa situação de situação emergencial, o cenário que a educação pública enfrenta nos últimos anos deve servir de alerta para inovações futuras, pela necessidade de melhor investimento na educação, seja ela publica ou privada. E, assim, criaremos novas formas de estudo, isto é, escolas conectadas capazes de oferecer métodos de estudos eficazes, estando conectadas às novas formas de busca de saberes educacionais, com visão nas estratégias do uso da tecnologia para o 
Rev. Interd. em Cult. e Soc. (RICS), São Luís, v. 7, n. 2, p. 214- 223, jul./dez. 2021 ISSN eletrônico: 2447-6498

aprendizado, em que expresse no seu currículo, como nas práticas pedagógicas, que tanto serão adotadas pelos educadores como pela instituição. Podemos ressaltar que, neste novo cenário, tanto os educadores como os gestores devem possuir competências digitais, isto é, letramento digital, a qual deverá englobar conhecimento das ferramentas digitais, habilidades pedagógicas, cidadania digital, bem como desenvolvimento profissional na sua atuação.

Em relação às medidas de situação emergencial que foram tomadas para desacelerar o contágio, com a suspensão das aulas em formato presencial, medidas essas para combater à disseminação novo coronavírus, geraram um grande impacto nos alunos e nos educadores, exigindo um esforço maior do poder público para um planejamento voltado para o novo formato de aulas online, exigindo um esforço de articulação voltado para a educação. Tal contexto evidencia que a educação, seja ela publica ou privada, é um pilar fundamental para a reconstrução de um País após uma crise de enfrentamento da pandemia, que atingiu as áreas da saúde, economia, entre outros.

Pensado neste contexto as Instituições de ensino seja ela tradicional ou moderna, cabe ao sujeito ser flexível diante a novos desafios tecnológicos, ser capaz de lidar com novas mudanças aprendendo novas habilidades no seu campo de experiência, lidando com constantes adaptações em curto espaço de tempo, sendo hábil no seu fazer de educador.

Sabendo enfrentar um novo método de abordagem de aprendizado em relação nova projeção, seja ela de organização do trabalho ou enfrentamento de aprendizado com base em ferramentas tecnológicas da informação como fonte de aprendizado. Podemos ressaltar que o uso das ferramentas tecnológicas na educação deve ser observado sob a ótica de uma nova metodologia de ensino e aprendizagem, assim, sendo, possibilitando a interação digital dos educandos com os conteúdos, isto é, o aluno passa a interagir com diversas ferramentas que o possibilitam a utilizar os seus esquemas mentais a partir do uso racional e mediando o uso da informação. Sendo o mesmo um conjunto de elementos que torna possível o desenvolvimento da sociedade.

\section{O NOVO COVID-19 E A SUSPENSÃO DAS ATIVIDADES EDUCACIONAIS}

Segundo o Ministério da Saúde (2020), o Novo Coronavírus é causador de infecções respiratórias como o resfriado comum. O novo coronavírus (SARS-CoV-2) foi identificado na cidade Wuhan China em dezembro de 2019. A infecção humana por esse vírus é chamada COVID-19. A principal forma de transmissão pode ocorrer de pessoa para pessoa, pelo ar ou por 
Rev. Interd. em Cult. e Soc. (RICS), São Luís, v. 7, n. 2, p. 214- 223, jul./dez. 2021

ISSN eletrônico: 2447-6498

contato pessoal com secreções contaminadas, como gotículas de saliva, espirro, tosse, catarro e contato com objetos ou superfícies contaminadas, seguido de contato com a boca, nariz ou olhos.

Para a Organização Mundial da Saúde (2020), pode-se estar com o COVID - 19 por até 14 dias antes de se apresentarem os sintomas, que são febre, cansaço e tosse seca. A maioria das pessoas (cerca de 80\%) se recupera da doença sem a necessidade de tratamentos especiais. De acordo com o Ministério da Saúde (2020), em casos mais raros, o mesmo pode atingir um quadro clínico mais grave e até fatal. Idosos e pessoas com outras condições médicas vulnerareis (como asma, diabetes e doença cardíaca) são vulneráveis a desenvolver problemas mais sérios.

A Organização Mundial da Saúde (2020) declarou em 30 de janeiro de 2020 que a pandemia do COVID - 19 se constitui em uma Emergência de Saúde Pública de Importância Internacional (ESPII), o mais alto nível de alerta emergencial da Organização, conforme previsto no Regulamento Sanitário Internacional.

Diante do exposto, para conter a disseminação do coronavírus e colapso no sistema único de saúde pública, necessitou da colaboração, cooperação e a solidariedade mundial, para conter o avanço da doença, e para isso, foram tomadas uma série de medidas sanitárias, entre elas, a quarentena ou popularmente chamado de isolamento social, bem como o isolamento verticalizado das pessoas sintomáticas ou assintomáticas, em investigação clínica e laboratoriais, de forma a evitar a propagação do vírus e transmissão local, orientado pelo Ministério da Saúde (2020).

Assim sendo, com o avanço de inúmeros de caso a cada dia de pessoas infectadas pelo COVID - 19, as escolas e instituições de ensino público e privados de educação básica à superior tiveram suas atividades interrompidas para conter o avanço da pandemia no país, conforme a Portaria no 343/2020, do Ministério da Educação.

\section{DA PORTARIA N 343/2020 QUE ESTABELECE O ENSINO REMOTO}

O Ministério da Educação publicou a portaria n 343 publicada no Diário Oficial da União, em 18 de março de 2020, que dispõe sobre a substituição das aulas presenciais por aulas em meios digitais enquanto durar a situação de pandemia do COVID - 19 (BRASIL, 2020). A medida é válida por 30 dias ou enquanto durar a situação da pandemia. Por meio da portaria, o MEC resolve 
Rev. Interd. em Cult. e Soc. (RICS), São Luís, v. 7, n. 2, p. 214- 223, jul./dez. 2021 ISSN eletrônico: 2447-6498

nos limites estabelecidos pela legislação em vigor, por instituição de educação superior integrante do sistema federal de ensino, de que trata o art. $2^{\circ}$ do Decreto $n^{\circ} 9.235$, de 15 e dezembro de 2017 (BRASIL, 2020, p.01).

A Portaria ressalta, ainda, que as Instituições de Ensino, integrantes do sistema federal de ensino, devem comunicar ao MEC, por meio de Ofício, a opção que será adotada como medida de prevenção ao COVID-19, em caráter excepcional, a substituição das disciplinas presenciais, em andamento, por aulas que utilizem meios e tecnologias de informação e comunicação, nos limites estabelecidos pela legislação em vigor, por instituição de educação superior integrante do sistema federal de ensino, de que trata o art. $2^{\circ}$ do Decreto $\mathrm{n}^{\circ} 9.235$, de 15 de dezembro de 2017.

Art. $2^{\circ}$ Suspensão das atividades acadêmicas presenciais, desde que cumpram os dias letivos e horas/aula estabelecidos na legislação em vigor; Alteração do calendário de férias, desde que cumpram os dias letivos e horas-aula estabelecidos na legislação em vigor (BRASIL, 2020, p.01).

A Organização das Nações Unidas para a Educação a Ciência e a Cultura (UNESCO), em resposta aos atuais desafios encontrados pela pandemia da Covid - 19, e seus enfrentamentos pela sociedade e as interrupções das atividades educacionais devido a pandemia, que afeta mais de 1,57 bilhão de estudantes em 191 países, o Instituto Internacional para Tecnologias da Informação na Educação (IITE) da UNESCO, propõe novas paradigmas de ensino como forma de aprendizado.

Diante do exposto, as instituições vêm buscando a cada dia formas de aprendizagem por meio da tecnologia da informação, buscando alternativas de forma a passa a seus educandos de forma remota um novo modelo de educação, para dar continuidade às aulas. Neste sentido, a tecnologia das informações digitais se torna um recurso de interação para mediação aluno, professor e familiares no processo de interação para um novo modelo de aprendizagem.

\section{A MOTIVAÇÃO E O AUTOESTIMA PELO INTERESSE DOS ESTUDOS}

Vários são os desafios que foram colocados pelo COVID-19: o processo de estímulo ao ensino e aprendizagem, assim como o papel do educador em face dos novos tempos e recursos da tecnologia digital na educação. Os professores e alunos necessitam emergir de maneira mais rápida e impactante no processo de aprendizagem com o uso das ferramentas tecnológicas no modelo de aprendizagem por aulas remotas, uma vez que esse processo é visto como forma ponderada a estimular o aprendizado em meio a pandemia. 
Rev. Interd. em Cult. e Soc. (RICS), São Luís, v. 7, n. 2, p. 214- 223, jul./dez. 2021 ISSN eletrônico: $2447-6498$

Convém ressaltar, que nesse momento, o ensino remoto emergencial toma novas dimensões no Brasil, no processo de educação. Assim sendo, essa nova dimensão dada às famílias em tempo de pandemia, mostra-se um acréscimo de problemas na educação dos filhos, uma vez que muitos pais não acompanha a evolução tecnológica, não possuindo o conhecimento necessário das ferramentas digitais, isto é, a modalidade de educação a distância (EAD), em ambientes virtuais de aprendizagem (AVA). Tendo em vista, que o ensino remoto ainda é a melhor saída para minimizar o atraso no retorno às aulas presenciais.

Mesmo com o desafio do conhecimento necessário das ferramentas digitais, diante dessa realidade passa a existir uma desmotivação generalizada por parte dos pais. É relevante abordar, que a responsabilidade recai mais uma vez ao professor o único responsável pelo incentivo do ensino aprendizagem dos alunos, bem como o motivador dos pais a valorizar as aulas em home Office, para não elevar o número de evasão escolar e nem de repetência. No que se refere a família tem papel fundamental no processo educativo das crianças e adolescente, papel conferido inclusive pelo Art. 205:

A educação, direito de todos e dever do Estado e da família, será promovida e incentivada com a colaboração da sociedade, visando ao pleno desenvolvimento da pessoa, seu preparo para o exercício da cidadania e sua qualificação para o trabalho. (BRASIL, 1988, p.124).

Como a escola desenvolve suas atividades com um grupo específico, é fundamental que este tenha pleno conhecimento da psicologia educacional do Estatuto da Criança e Adolescente e das políticas educacionais, objetivando melhorar a qualidade do processo ensino aprendizagem.

Contudo, é necessário fazer com que o aluno desenvolva o gosto pela aprendizagem e obtenha um melhor rendimento. Por conseguinte, esta preocupação com o desenvolvimento do discente requer esforços do corpo docente e da equipe pedagógica, empreendendo iniciativas focadas a estimular a família para participação no processo de aprendizagem, bem como, no processo de motivação dos filhos, encontrando um cenário ideal e adequado que se caracterize um lugar importante para o desempenho das atividades escolar em tempo de pandemia.

\section{TECNOLOGIAS DIGITAIS APLICADAS A EDUCAÇÃO}

A partir da necessidade do distanciamento social em tempos de pandemia, a população, em geral, passou a ressignificar o uso de ferramentas tecnológicas já conhecidas para compor o novo cenário de educar, no qual surgem as ferramentas digitais no processo de aprendizagem. 
Rev. Interd. em Cult. e Soc. (RICS), São Luís, v. 7, n. 2, p. 214- 223, jul./dez. 2021 ISSN eletrônico: $2447-6498$

Com a falta de conhecimento e experiências das tecnologias por parte de professores e alunos, na aplicabilidade do uso dos softwares como ferramenta de ensino e de aprendizagem, se torna um obstáculo na prática pedagógica.

Sob outro prisma, o mundo contemporâneo vivencia uma sociedade da informação, em que os jovens desde cedo estão em contato com o mundo informatizado por meio das redes sociais dos equipamentos como celular, computador, games e entre outros, embora isso não equivale a ter uma melhor interação entre educação através meios digitais. Neste cenário, podemos observar que na sala de aula persiste uma situação antagônica de forma de aprendizado entre professor e aluno, em que os alunos aspiram por uma forma de ensino mais dinâmica, enquanto os professores, por sua vez, persistem em práticas pedagógicas tradicionais, utilizando de recursos convencionais.

Neste sentido, o docente necessita repensar sobre o seu papel de educador e o novo prisma da tecnologia da informação no processo de educar, edificando uma nova escola com usos das ferramentas como interface no processo de ensino e aprendizagem, lançando mão das ferramentas de informação digital. O uso de tecnologias digitais como prática no processo de aprendizagem, o qual está inserido na Constituição, implica nos aprimoramentos dos métodos de pesquisas e ensino por parte dos discentes, no sentido de fomentar um maior dinamismo no ato de educar, como é citado por Carvalho (2014, p.02).

A promulgação da Constituição Federal de 1988 e da Lei de Diretrizes e Bases da Educação Nacional (9.394/96) nos seus aspectos constitutivos, deliberaram o compromisso do poder público em propiciar investimentos tecnológicos para o desenvolvimento de atitudes de gestão compatíveis com as exigências globais, conferindo aos sujeitos a responsabilidade de ultrapassar os dogmas burocráticos e funcionalistas que tornaram o espaço escolar impermeável e rígido às mudanças.

As principais ferramentas virtuais mais utilizadas no meio educacional são: Google Classroom e Moodle, são ferramentas digitais voltadas para auxiliar as atividades escolares, uma ferramenta de streaming, dando formas às aulas síncronas e outro como ambiente virtual de aprendizagem, como forma de acompanhamento das práticas pedagógicas.

O Google Sala de aula (Google Classroom) é um sistema de gerenciamento com tópicos escolares, de forma dinâmica com interação e de fácil manuseio, sendo o mesmo um recurso do aplicativo do Google voltados para área de educação, lançado para o público em geral em 2014. 
Rev. Interd. em Cult. e Soc. (RICS), São Luís, v. 7, n. 2, p. 214- 223, jul./dez. 2021 ISSN eletrônico: $2447-6498$

O Ensino remoto utilizado atualmente em caráter emergencial no Brasil, assemelha-se a EAD apenas no que se refere a uma educação mediada pela tecnologia. Mas os princípios seguem sendo os mesmos da educação presencial, (CORDEIRO et al; COSTA, 2020).

Em contrapartida, o Moodle é uma plataforma relevante apoio ao ensino online, que tem como finalidade apoiar suas necessidades educacionais e treinamentos, assim como outras plataformas. Por esse ângulo, o aprendizado é de forma acessível a qualquer pessoa, a jornada de aprendizado poderá permanecer consistente, envolvente e individualizada.

\section{CONSIDERAÇÕES FINAIS}

Podemos concluir que a experiência educacional de alunos e professores no período de Pandemia, em que processo do estímulo ao ensino e aprendizagem e o papel do educador em face dos novos tempos e recursos da tecnologia digital na educação. Neste sentido, percebemos que foi introduzida sem planejamento prévio, tornando desafiador o uso dessas ferramentas tecnologias.

Desta forma, a educação passou por mudanças relevantes nesses últimos meses. Consequentemente, a vida dos discentes que tiveram que se adaptar à nova realidade sem a convencional, aula presencial, sem a figura do professor em forma física, assim como também, muitas vezes sem ferramentas necessárias para as aulas com mais qualidades. Outro aspecto percebido foi a falta de conhecimento por parte de alguns professores, por não ter domínio do conhecimento prático de tais ferramentas digitais.

Assim sendo, o uso dessas novas tecnologias educacionais, um dos pontos, contribuíram para ver a necessidade de melhoramento em diversos aspectos educacionais, tais como; criação de novas habilidades tanto de ensino, o papel e função do docente, quanto uma nova visão de aprendizagem, por parte do discente, que deixará de lado o método pedagógico tradicional de sala de aula. Não podemos deixar de sublinhar que se tratam de processos de mudanças nos âmbitos sociais, políticos, econômicos e ambientais, os quais são modos de percebemos as mutações que ocorrem no sistema capitalista; tais no levam a pensar em como poderemos criar meios de resistências aos fascismos crescentes, construindo novas de maneiras de nos relacionarmos tanto com as maquinas inteligentes quanto com o meio ambiente para que tudo caminhe em direção à vida mais potente, inventiva e criativa, sobretudo na diminuição da desigualdade e da intolerância em todos os níveis. 
Rev. Interd. em Cult. e Soc. (RICS), São Luís, v. 7, n. 2, p. 214- 223, jul./dez. 2021 ISSN eletrônico: 2447-6498

\section{REFERÊNCIAS}

BRASIL. Portaria $\mathbf{N}^{\circ}$ 343, de 17 de março de 2020. Dispõe sobre a substituição das aulas presenciais por aulas em meios digitais enquanto durar a situação de pandemia do Novo Coronavírus - COVID-19. D.O.U 18/03/2020. Disponível em: <http://www.in.gov.br/en/web/dou/-/portaria-n-343-de-17-de-marcode-2020-248564376>. Acesso em: 19 de julho de 2020.

BRASIL. Constituição (1988). Constituição da República Federativa do Brasil. Brasília, DF: Centro Gráfico, 1988.

CARVALHO, Marcelino. Revista Científica do Instituto Federal de Alagoas, Junho de 2014. p. 02.

CORDEIRO, Karolina Maria de Araújo, O impacto da Pandemia na educação: a utilização da tecnologia como ferramentas de ensino. Universidade Federal do Amazonas, 2020. p. 02 a 09.

$<$ http://repositorio.idaam.edu.br/jspui/handle/prefix/1157>. Acesso em 08/01/2021

COSTA, Renata. Lições do Corona vírus: Ensino remoto emergencial não é ead. Desafios da

Educação.02.04.2020. Disponível em: https://desafiosdaeducacao.grupoa.com.br/coronavirus-ensinoremoto> Acesso em: 08 janeiro 2021.

FREIRE, Paulo, Pedagogia da autonomia: Saberes necessário à prática educativa, paz eterra $6^{\mathrm{a}}$ edição; SP 1996.

GOOGLE CLASSROOM. Google for education. [S.1.: s.n.], 2020. Disponível em: < classroom.google.com>. Acesso em: 16 de julho de 2020.

GOOGLE CLASSROOM, disponível em<https://www.techtudo.com.br/noticias/2020/04/como-funcionao-google-classroom-saiba-tudo-sobre-a-sala-de-aula-online.ghtml>,29 de julho de 2020.

MINISTÉRIO DA SAÚDE. Painel Coronavírus (COVID - 19). 2020. Disponível em: <https://covid.saude.gov.br/>. Acesso em: 17 de julho de 2020.

OLIVEIRA, Rosiska Darcy, Oliveira, Miguel Darcy; CecconClaudius - A vida na Escola e a Escola da Vida. Vozes, $19^{\text {a }}$ Ed, Petrópolis, 1998.

PLATAFORMA MOODLE disponível em < https://moodle.com/pt/> acessado em 29 de julho de 2020.

REVISTA EXAME. Quem vai salvar a economia do coronavírus? Disponível em $:<$ https://exame.com/revista-exame/quem-vai-salvar-a-economia> Acesso em: 08 janeiro 2021. São Paulo: Papirus, 2004.

TEIXEIRA, João de Fernandes. A mente pós evolutiva: a filosofia da mente no universo de silício, Petrópolis, Vozes, 2010.

UNESCO. Organização das Nações Unidas para a Educação, a Ciência e a Cultura. 2020. Disponível em: <https://nacoesunidas.org/agencia/unesco/>. Acesso em: 18 de julho de 2020. 